\title{
Glutamate uptake in retinal glial cells during diabetes
}

Received: 5 July 2004 / Accepted: 11 September 2004 / Published online: 2 February 2005

(C) Springer-Verlag 2005

\begin{abstract}
Aims: Glutamate recycling is a major function of retinal Müller cells. The aim of this study was to evaluate the expression and function of glutamate transporters during diabetes. Methods: Sprague-Dawley rats were rendered diabetic by a single dose of streptozotocin (50 $\mathrm{mg} / \mathrm{kg}$ ). Following 12 weeks of diabetes, immunolocalisation and mRNA expression of the two glial cell transporters, GLAST and EAAT4 were evaluated using indirect immunofluorescence and real-time PCR. The function of glutamate transport was investigated at 1, 4 and 12 weeks following induction of diabetes by measuring the level of uptake of the non-metabolisable glutamate analogue, D-aspartate, into Müller cells. Results: There was no difference in the localisation of either GLAST or EAAT4 during diabetes. Although there was a small apparent increase in expression of both GLAST and EAAT4 in diabetic retinae compared with controls this was not statistically significant. At 1, 4 and 12 weeks following diabetes, D-aspartate immunoreactivity was significantly increased in Müller cells of diabetic rats compared to controls $(p<0.001)$. The $\mathrm{EC}_{50}$ was found to increase by $0.304 \log$ units in diabetic Müller cells compared with controls, suggesting that glutamate uptake is twice as efficient. Conclusions: These
\end{abstract}

M. M. Ward · E. L. Fletcher $(\bowtie)$

Department of Anatomy and Cell Biology,

The University of Melbourne,

Grattan St,

Parkville, 3010, Victoria, Australia

e-mail: elf@unimelb.edu.au

Tel.: +61-3-83443218

Fax: $+61-3-93475219$

\section{A. I. Jobling}

Department of Optometry and Vision Sciences,

The University of Melbourne,

Parkville, 3010, Victoria, Australia

M. Kalloniatis

Department of Optometry and Vision Science,

University of Auckland,

Auckland, New Zealand data suggest that there are alterations in glutamate transport during diabetes. However, these changes are unlikely to play a significant role in glutamate-induced neuronal excitoxicity during diabetes. These results suggest that although Müller cells undergo gliosis at an early stage of diabetes, one of the most important functions for maintaining normal retinal function is preserved within the retina.

Keywords Diabetes - EAAT1 - GLAST - Glutamate · Müller cell $\cdot$ Retina $\cdot \mathrm{STZ}$

Abbreviations DAB: di-amino-benzidene EAAC1: excitatory amino acid carrier 1 - EAAT: excitatory amino acid transporter - GABA: $\gamma$-amino-butyric acid - GLAST: glutamate-aspartate transporter - GSPBS: goat serum in phosphate buffered saline - INL: inner nuclear layer - IPL: inner plexiform layer - NGS: normal goat serum - NMDA: $\mathrm{N}$-methyl-D-aspartate $\cdot \mathrm{ONL}$ : outer nuclear layer $\cdot \mathrm{PB}$ : phosphate buffer - PCR: polymerase chain reaction - STZ: streptozotocin

\section{Introduction}

Diabetic retinopathy is the leading cause of blindness in those of working age. A major factor in the pathogenesis of this condition is alterations in retinal vasculature, and subsequent neovascularisation. In addition to the vascular changes there are also a range of abnormalities of neuronal function that occur early in diabetes (for review, see [1]). This neuronal dysfunction is manifest as alterations in colour vision [2, 3], dark adaptation and electrophysiology [4-7]. Because such neuronal changes occur early in the disease process, it has been suggested that they may ultimately be linked with the retinal vascular pathology.

Müller cells are vital for maintaining the integrity of the retina [8]. They are actively involved in uptake and degradation of the amino acid neurotransmitters, glutamate and GABA, are involved in shuttling energy metabolites to neurons and are also important for maintenance 
of the blood-retinal barrier [9-11]. Astrocytes are intricately linked with the vasculature and have processes within the nerve fibre and ganglion cell layers [12]. The function of astrocytes within the retina is not clearly defined, although they do express glutamate transporters such as GLAST and EAAT4 $[13,14]$. Highlighting the potential importance of these glutamate transporters in retinal pathology, studies have reported increased glutamate concentrations within the vitreous of patients with diabetes and in diabetic retinae $[15,16]$.

Glutamate is the major excitatory neurotransmitter within the retina and brain [17]. In order to maintain normal retinal function, glutamate must be removed rapidly from the synaptic cleft. At the molecular level, five glutamate transporters have been cloned: excitatory amino acid transporters (EAAT) $1-5$, all of which have been identified in the retina $[13,14,18-22]$. Although the function of specific transporter types is contentious, it is clear that GLAST (EAAT1) is the predominant transporter for removal of glutamate within the retina and defects in its function lead to major deleterious effects on vision [20, 23, 24].

Several studies have suggested that Müller cells are abnormal in diabetes. They express glial fibrillary acidic protein following one month of diabetes [16]. Furthermore, the level of glutamate within the vitreous of patients with diabetes and in diabetic rat retinae is elevated [15, 16]. However, the major enzyme involved in glutamate degradation within Müller cells, glutamine synthetase, is only moderately affected $[25,26]$. These studies suggest that glutamate transport within the retina during diabetes might be abnormal. Indeed, a recent study showed reduced glutamate uptake in isolated Müller cells, suggesting that GLAST function in these cells is altered in the STZ rat model of diabetes [27]. However, it should be emphasised that Li and Puro [27] examined 1-trans-pyrrolidine-2,4dicarboxylate (a glutamate analogue that is transported into Müller cells via GLAST)-induced currents in isolated Müller cells. Glutamate uptake and expression of glutamate transporters can be affected by the external milieu, in particular serum factors and plasma [28, 29]. Therefore it is important to examine glutamate uptake in an in vivo situation.

The aim of this project was to examine the changes in glutamate transporter expression and function during diabetes using an in vivo model of type 1 diabetes. We used immunocytochemistry and semi-quantitative real-time PCR to examine the expression of GLAST and EAAT4 in the control and diabetic rat retinae and also measured the function of the GLAST transporter by determining the extent of uptake of the non-metabolisable glutamate analogue, D-aspartate.

\section{Materials and methods}

Animals Male Sprague-Dawley rats, aged 6 to 7 weeks, were injected with either a single dose of streptozotocin (STZ; $50 \mathrm{mg} / \mathrm{kg}$; Sigma Chemical, St Louis, MO, USA) dissolved in $0.1 \mathrm{~mol} / 1$ citrate buffer, $\mathrm{pH} 4.5$, or citrate buffer alone. Only diabetic animals with a blood glucose level of $\geq 15 \mathrm{mmol} / 1$ were included in the study. Diabetic animals were given two units of long-acting insulin daily to maintain body weight and prevent ketoacidosis without lowering blood glucose levels. All animals had free access to rat food and water. Table 1 illustrates the effects of treatment on blood glucose and glycosylated haemoglobin, in diabetic and control animals. All experiments were performed in accordance with the guidelines for the welfare of experimental animals issued by the Federal Government of Australia, and the National Health and Medical Research Council. The Principles of Laboratory Care ublished by the National Institute of Health (publication no. 85-23, revised 1985; http:/grants1.nih.gov/grants/ olaw/references/phspol.htm) were followed. Following 1, 4 and/or 12 weeks of diabetes, control and diabetic rats were deeply anaesthetised with xylazine/ketamine (60:5 $\mathrm{mg} / \mathrm{kg}$, Therapon Pty Ltd, Burwood, Victoria, Australia) and either killed by anaesthetic overdose with pentobarbital (72 mg/kg; RNA isolation, immunocytochemistry) or injected intravitreally with D-aspartate or sham injections of phosphate buffered saline.

EAAT4 and GLAST immunocytochemistry In order to examine the protein expression of GLAST and EAAT4, control and diabetic rat eyes were enucleated, the anterior segment and vitreous removed, and the posterior eyecup placed in a chilled fixative containing $4 \%$ paraformaldehyde in $0.1 \mathrm{~mol} / 1$ phosphate buffer (PB) for $30 \mathrm{~min}$. Following fixation, the retinae were dissected from the eyecup, cryoprotected in graded sucrose solutions $(10,20,30 \%)$, and either sectioned vertically at $12 \mu \mathrm{m}$ on a cryostat, or processed free-floating as flat-mounts.

A guinea-pig polyclonal antiserum directed against the C-terminus of GLAST (AB\#1782; Chemicon International, CA, USA; diluted 1:1,000) was used to evaluate changes in the localisation of GLAST during diabetes. A polyclonal affinity-purified antiserum directed against a 21 amino acid synthetic oligopeptide corresponding to the C-terminus of rat EAAT4 was used to immunolabel EAAT4 (Alpha Diagnostic Int., San Antonio, TX, USA, diluted 1:100).

Immunocytochemical labelling was carried out using indirect immunofluorescence or avidin-biotin-peroxidase complex $(\mathrm{ABC})$ method. Retinal sections were blocked for $1 \mathrm{~h}$ in a solution containing 10\% normal goat serum (NGS), $1 \%$ bovine serum albumin (BSA), $0.05 \%$ Triton-X-100 in PB. The primary antibodies were diluted in $3 \%$ NGS, $1 \%$

Table 1 Animal characteristics

\begin{tabular}{|c|c|c|c|c|}
\hline \multirow{2}{*}{$\begin{array}{l}\text { Duration of } \\
\text { diabetes } \\
\text { (weeks) }\end{array}$} & \multicolumn{2}{|c|}{$\begin{array}{l}\text { Blood/glucose } \\
(\mathrm{mmol} / \mathrm{l} \pm \mathrm{SEM})\end{array}$} & \multicolumn{2}{|c|}{$\mathrm{HbA}_{1} \mathrm{C} \pm \mathrm{SEM}$} \\
\hline & Control & Diabetic & Control & Diabetic \\
\hline 1 & $6.1 \pm 0.211$ & $23.8 \pm 1.156$ & & \\
\hline 4 & $5.4 \pm 0.297$ & $23.9 \pm 0.587$ & & \\
\hline 12 & $5.1 \pm 0.191$ & $25.7 \pm 0.739$ & $3.7 \pm 0.120$ & $16.5 \pm 0.340$ \\
\hline
\end{tabular}


BSA, $0.05 \%$ Triton-X-100 in PB, and applied overnight at room temperature. After washing in PB, either goat-antirabbit IgG, goat-anti-guinea pig conjugated to Alexa TM 594, goat-anti-guinea pig conjugated to Alexa TM 488 or biotinylated goat-anti-rabbit secondary antibodies were applied for $1 \mathrm{~h}$ (Molecular Probes, Eugene, OR, USA; diluted 1:500). For the ABC method, retinal flat-mounts were subsequently incubated in solutions from the Vectastain Elite $\mathrm{ABC}$ Kit (Vector Laboratories, Burlingame, CA, USA) in $\mathrm{PB}$ for $1 \mathrm{~h}$. Retinae were rinsed in two changes of $\mathrm{PB}$ and two changes of $0.05 \mathrm{~mol} / \mathrm{l}$ Tris- $\mathrm{HCl}$ buffer for $5 \mathrm{~min}$, then incubated in $0.05 \%$ 3,3-diamonbenzidine tetrahydrochloride $(\mathrm{DAB})$ in Tris buffer for $10 \mathrm{~min}$. Hydrogen peroxide was added to the incubation medium to a final concentration of $0.01 \%$. Following $5 \mathrm{~min}$ the reaction was stopped by rinsing in Tris buffer. Sections were then washed and coverslipped.

Microscopical analysis Immunofluorescent sections were examined and imaged with a Zeiss Axioplan 2 microscope (Zeiss, Oberkochen, Germany), fitted with a Bio-Rad 1024 confocal illuminating system (Bio-Rad, Sydney, Australia), using $\times 40, \times 63$ and $\times 100$ objectives. The appropriate fluorescence filters were used (Alexa TM 594/CY3, excitation -568 , emission filter 605/32; Alexa TM 488/FITC, excitation -488 , emission filter 522/32) with a krypton/argon laser for differential visualisation of the fluorophores. Red and green fluorescence was scanned and imaged separately and later merged with Adobe Photoshop 7.0 (Adobe Systems, USA). Retinal flatmounts that had been prepared using the $\mathrm{ABC}$ method were viewed on a Zeiss Axioplan II microscope with a $\times 40$ oil objective.

Expression of GLAST and EAAT4 In order to examine changes in mRNA expression of GLAST and EAAT4, the eyes from control and diabetic rats were removed, the anterior contents discarded and the retina dissected free from the posterior eyecup. The retinae were then snap frozen in liquid nitrogen and stored at $-70^{\circ} \mathrm{C}$ until use.

$R N A$ isolation and RT-PCR Total RNA was isolated from individual rat retinae (10-30 $\mathrm{mg}$ ) using the RNeasy mini kit (Qiagen, Chatsworth, CA, USA). To eliminate potential genomic DNA contamination, a DNase I treatment was included in the isolation protocol. The purified RNA was quantified at $260 \mathrm{~nm}$ on a spectrophotometer (Perkin Elmer Corp., Norwalk, CT, USA) and 0.5 $\mu \mathrm{g}$ RNA was reverse transcribed (Omniscript RT kit; Qiagen, Chatsworth, CA, USA) using $0.5 \mu \mathrm{mol} / 1$ oligo-d(T) primers. Specific rat GLAST (5'-ctctgggcatcctcttcttg-3' and $5^{\prime}$-caaatctggtgatgegt ttg- $\left.3^{\prime}\right)$ and EAAT4 (5'-tatggcatccttggacaaca-3' and $5^{\prime}$-accag gtccatgaaagcatc- $\left.3^{\prime}\right)$ primers were designed and used $(0.5$ $\mu \mathrm{mol} / \mathrm{l}$ ) with commercial PCR reaction mix (HotstarTaq; Qiagen). A touchdown protocol $\left[95^{\circ} \mathrm{C}, 15 \mathrm{~min} ;\left(94^{\circ} \mathrm{C}, 10 \mathrm{~s}\right.\right.$; $70^{\circ} \mathrm{C}, 30 \mathrm{~s}$; decreasing $1{ }^{\circ} \mathrm{C} /$ cycle, $\left.72^{\circ} \mathrm{C}, 30 \mathrm{~s}\right) \times 15 ;\left(94^{\circ} \mathrm{C}\right.$, $\left.\left.10 \mathrm{~s} ; 55^{\circ} \mathrm{C}, 30 \mathrm{~s} ; 72^{\circ} \mathrm{C}, 30 \mathrm{~s}\right) \times 20 ; 72^{\circ} \mathrm{C}, 10 \mathrm{~min}\right]$ was run on a thermal cycler (Hybaid, Ashford, UK) and the identities Fcts were confirmed by automated DNA sequencing of both strands.
The relative expression levels of GLAST and EAAT4 were determined for rat retinae using real-time PCR (LightCycler; Roche, Mannheim, Germany). Total RNA was isolated and reverse transcribed as above. An aliquot of cDNA $(0.025 \mu \mathrm{g})$ added to a commercial reaction mix (FastStart DNA Master SYBR Green I; Roche) containing $3 \mathrm{mmol} / 1 \mathrm{MgCl}_{2}$ and $0.5 \mu \mathrm{mol} / 1$ of the respective primers. After an initial denaturation $\left(95^{\circ} \mathrm{C}, 10 \mathrm{~min}\right)$, a 40 -cycle protocol was used $\left(95^{\circ} \mathrm{C}, 0 \mathrm{~s} ; 60^{\circ} \mathrm{C}, 10 \mathrm{~s} ; 72^{\circ} \mathrm{C}, 12 \mathrm{~s}\right)$ with the fluorescent signal detected after the extension step. Hypoxanthine phosphorylribosyl transferase (HPRT) was used as the housekeeping gene. For the HPRT reactions, human primers (5'-ggaggccatcacattgtagc-3' and 5'-ccacaatc aagacattctttcc-3') were included and the final $\mathrm{MgCl}_{2}$ concentration was $4 \mathrm{mmol} / \mathrm{l}$. The amplification protocol was similar to that described for GLAST and EAAT4, however, a 15 -s extension time was used and the fluorescence signal detected at $82^{\circ} \mathrm{C}$ for $2 \mathrm{~s}$. While the human primers had one base pair mismatch in both oligonucleotides when compared to the rat sequence, a single product of the correct size was amplified. Sequencing of the product showed it to be rat HPRT. All amplifications were performed in triplicate and tissue GLAST and EAAT4 expression levels were corrected for HPRT content.

In vitro D-aspartate uptake assay D-Aspartate is a nonmetabolisable glutamate transporter analogue. By measuring the degree of D-aspartate uptake into Müller cells, we were able to examine the function of the glutamate transporter GLAST in Müller cells. In order to be able to examine the changes in uptake in control and diabetic retinae, it was first necessary to establish the concentration of D-aspartate that saturates the transporter. The eyes from six adult male Sprague-Dawley rats were removed, the anterior portion of the globe separated and the retinae dissected free from the posterior eyecup. Each retina was cut in half and incubated at $37^{\circ} \mathrm{C}$ in oxygenated AmesNesbett solution supplemented with D-aspartate at the following concentrations for $10 \mathrm{~min}$ : $0,0.01,0.03,0.1,0.3$ and $1 \mathrm{mmol} / \mathrm{l}$. Following $10 \mathrm{~min}$, the retinae were immediately removed and placed into chilled fixative and processed for post-embedding immunocytochemistry (as described below).

D-Aspartate uptake in control and diabetic retinae Following 1, 4 and 12 weeks, control and diabetic rats were prepared for D-aspartate assaying. The cornea of each rat was anaesthetised with $0.5 \%$ proxymetacaine (Ophthetic; Allergan, Frenchs Forest, NSW, Australia). Under deep anaesthesia (xylazine/ketamine; 60:5 mg/kg, Therapon Pty Ltd, Burwood, Victoria, Australia), the right eyes were slowly injected intravitreally with either $2 \mu$ of 0.67 $\mathrm{mmol} / \mathrm{l}[30]$ or $2 \mu \mathrm{l}$ of $2.5 \mathrm{mmol} / \mathrm{l} \mathrm{D}$-aspartate, a nonendogenous ligand of glutamate transporters that can be detected by immunocytochemistry [31]. Based on these injection concentrations and volumes, the final vitreal concentration was approximately 0.1 and $0.37 \mathrm{mmol} / 1 \mathrm{re}-$ spectively (assuming a rat vitreal volume of $13.36 \mu \mathrm{l}$ ). 
Following 30 min rats were killed by intracardial injection of pentobarbital and their eyes removed. The eyes were then placed in a chilled fixative solution containing $1 \%$ paraformaldehyde, $2.5 \%$ glutaraldehyde, $3 \%$ sucrose, $0.01 \%$ calcium chloride in $0.1 \mathrm{~mol} / 1$ phosphate buffer (pH 7.4). The tissue remained in the fixative for $24 \mathrm{~h}$, and was then rinsed with phosphate buffer and dissected. The anterior portion of the globe was removed and the retina was dissected into superior nasal and temporal, and inferior nasal and temporal sections through the optic nerve. The tissue was processed through a graded series of methanol washes $(75,85,95$ and $100 \%)$ and embedded in an epoxy resin (ProSciTech, Queensland, Australia). In order to minimise the effect of eccentricity, only pieces of retinae adjacent to the optic nerve were embedded. The samples were sectioned at $500 \mathrm{~nm}$ on an ultramicrotome (Reichert-Jung Ultracut S) and placed on Tefloncoated 18-well slides (Cel-line, Newfield, NJ, USA) and subsequently processed for serial-section post-embedding immunocytochemistry.

D-Aspartate immunocytochemistry The post-embedding immunocytochemical procedure used was that described by Kalloniatis and Fletcher [32]. The tissue sections were etched in 1:5 solution of sodium ethoxide/ethanol rinsed in a graded series of methanol washes and placed in phosphate buffer $(0.1 \mathrm{~mol} / \mathrm{PB})$. The slides were then placed in $1 \%$ sodium borohydride in $0.1 \mathrm{~mol} / 1$ phosphate buffer for $30 \mathrm{~min}$, washed, dried and blocked with a solution containing $5 \%$ goat serum, $0.8 \%$ bovine serum albumin, in phosphate buffered saline (pH 7.4) for $1 \mathrm{~h}$. Sections were then incubated overnight in rabbit anti-D-aspartate (kindly donated by Prof. R.E. Marc, University of Utah) diluted $1: 100$ in $1 \%$ goat serum in phosphate buffered saline (GSPBS). Following the incubation with the primary antibody, the slides were rinsed in 1\% GSPBS for $30 \mathrm{~min}$. The secondary antibody, goat anti-rabbit IgGs conjugated with 1-nm gold and diluted 1:100 in 1\% GSPBS, was applied for $4 \mathrm{~h}$ (gold conjugates purchased from British BioCell International, UK). The slides were then rinsed several times in phosphate buffered saline (PBS) and fixed in $1 \%$ glutaraldehyde in $0.1 \mathrm{~mol} / 1$ phosphate buffer for $10 \mathrm{~min}$. The immunogold was visualised by silver intensification $[32,33]$.

Quantification of D-aspartate immunoreactivity For quantification purposes, all experiments were performed under identical conditions. That is, retinal sections from each animal were placed on the same 18-well slide and processed at the same time using identical solutions and antibody aliquots. In all experiments, the level of immunoreactivity was measured in each of 30 Müller cell somata from each retinal piece. Images were captured using a Kodak Megaplus high-resolution camera mounted on a Zeiss Axioplan II microscope with a $\times 40$ oil objective and $\times 10$ eye piece. The histogram option of NIH Image 1.49 (NIH, Bethesda, MD, USA) was used to determine the average pixel value over each of 30 Müller cell somata with 8 -bit precision (i.e. pixel values range from 0 to 255 or $2.408 \log$ units). Consequently, each pixel value is equivalent to $0.0094 \log$ units of change in immunoreactivity. The level of immunoreactivity (pixel value) determined
Fig. 1 Vertical cryostat sections of the control (a) and diabetic (b) rat retinae labelled for the glutamate transporter, GLAST following 12 weeks of diabetes. GLAST labels Müller cell somata and their processes that span the retina from the outer limiting membrane to the inner limiting membrane. There was no apparent change in labelling following the onset of diabetes. Scale bar $=50 \mu \mathrm{m}$. Flatmount preparation of control (c) and diabetic (d) rat retinae labelled for EAAT4. EAAT4 labels astrocytes within the nerve fibre layer. There was no apparent difference in labelling in control compared with diabetic retinae. $O N L$ outer nuclear layer, $O P L$ outer plexiform layer, $I N L$ inner nuclear layer, $I P L$ inner plexiform layer, $G C L$ ganglion cell layer. Scale bar $=20 \mu \mathrm{m}$
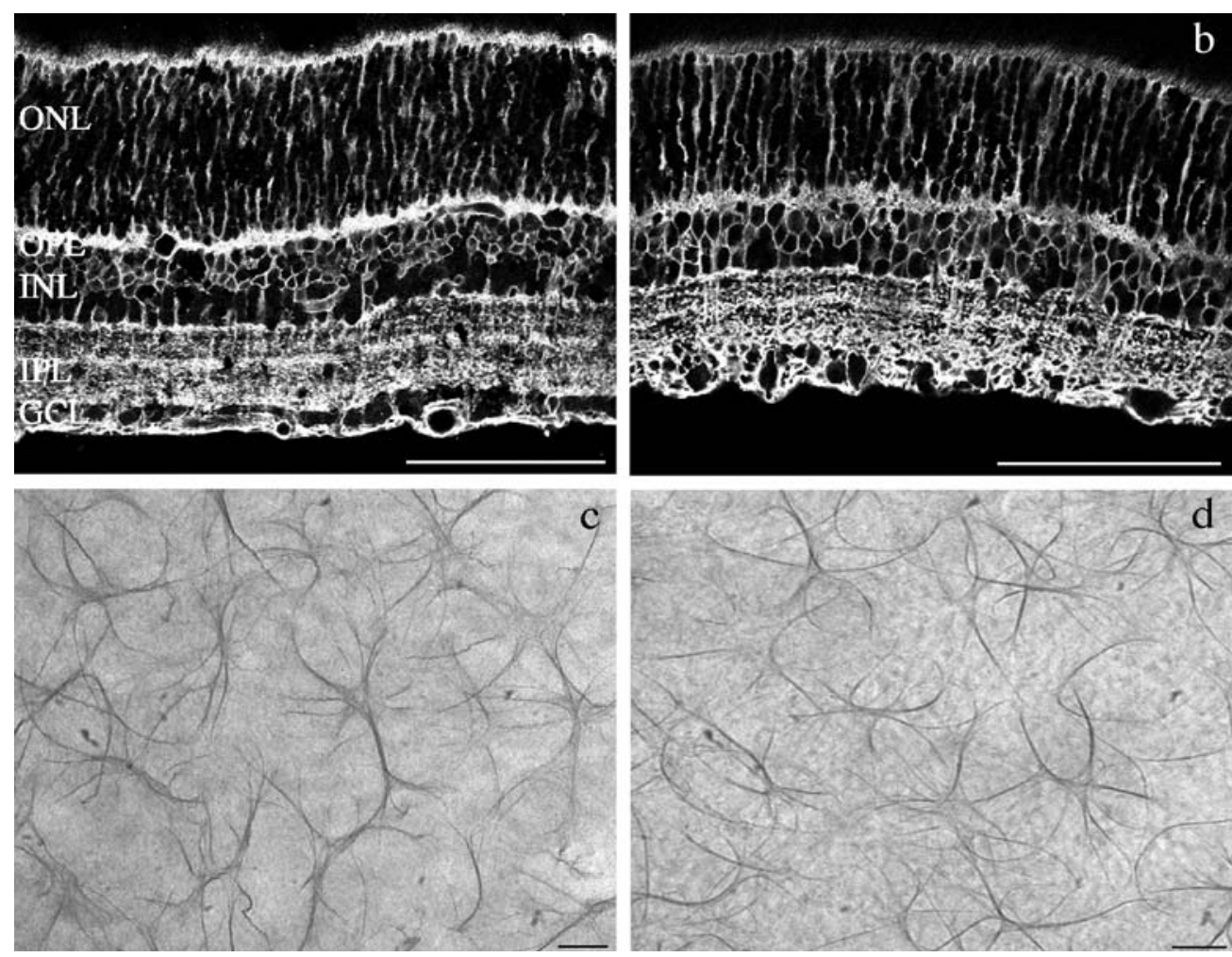
using these methods is proportional to the logarithm of the concentration of antigen in the tissue [34-36].

A dose-response curve was generated for tissue that had been incubated in varying concentrations of D-aspartate. The data was fitted to a Michaelis-Menten equation. The lowest control in vitro value, determined from the incubation of retinae in $0 \mathrm{mmol} / \mathrm{l} \mathrm{D}$-aspartate was used to fix the lowest point of the curve. The mean pixel values obtained from the in vivo intravitreal injection experiment were fitted to the curve to determine the relative change in $\mathrm{EC}_{50}$ between controls and diabetic. The mean pixel value for each of the controls at 1, 4 and 12 weeks was floated to the modelled in vitro curve (i.e. the curve generated from the control in vitro experiment) of the in vitro data. If one assumes that the only change between the two treatment groups is a change in $K_{m}$ value, it is possible to make an estimation of the change in $\mathrm{EC}_{50}$ during diabetes. To do this the mean pixel values generated from the STZ animals were plotted on the modelled curve using the formula $\left(\mathrm{Y}=\right.$ bottom $+($ Top - Bottom $) /\left(1+10^{\wedge}\left(\left(\log \mathrm{EC}_{50}-\mathrm{X}\right)\right)\right)$. By doing this we were able to quantify the relative change in $\mathrm{EC}_{50}$ for D-aspartate uptake in control and diabetic retinae.

Statistical analysis Statistical analysis was performed using an ANOVA (Statview) and a $p$ value of less than 0.05 was considered statistically significant.

\section{Results}

Glutamate transporter expression in Müller cells and astrocytes during diabetes We evaluated the expression of GLAST and EAAT4 by immunocytochemistry and realtime PCR. Figure $1 \mathrm{a}$ and $\mathrm{b}$ show vertical cryostat sections of control and diabetic rat retinae following 12 weeks of diabetes that had been immunolabelled for GLAST. Consistent with previous reports, GLAST was localised within Müller cell processes within both plexiform layers and their endfeet in the inner limiting membrane $[13,21]$. We were unable to detect any large differences in immunoreactivity between control and diabetic retinae.

EAAT4 has been previously associated with glutamate uptake into Purkinje cells of the cerebellum. We have recently shown that EAAT4 is expressed by astrocytes in the retina [14]. Figure 1c and d shows EAAT4 labelling in whole-mounted control and diabetic rat retinae 12 weeks post-diabetogenesis. The labelling pattern looks very similar to the control, and we were unable to detect any differences in the level of EAAT4 in control compared with STZ animals.

In order to examine whether the mRNA expression levels of GLAST and EAAT4 are abnormal, we performed semi-quantitative real-time PCR, which is known to provide an accurate measure of gene expression. The rat HPRT gene was used to correct for mRNA. Figure 2 shows the relative expression of GLAST and EAAT4 in control and diabetic retinae 12 weeks post diabetogenesis. Although the expression of both GLAST and EAAT4 appears to

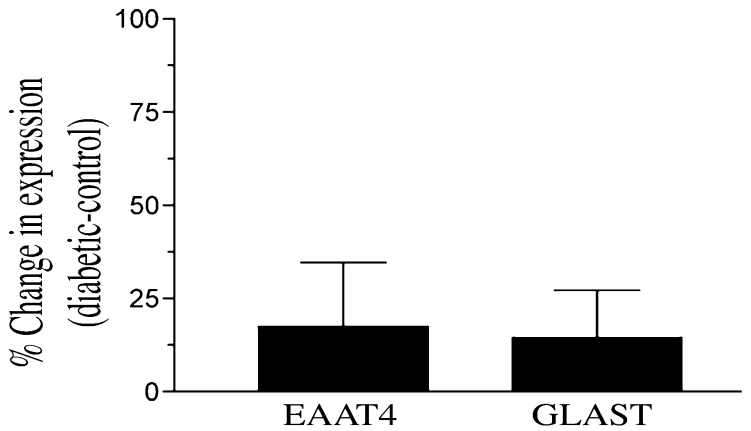

Fig. 2 Semi-quantitative analysis of GLAST and EAAT4 expression in control and diabetic rat retinae following 12 weeks of diabetes. Total RNA was isolated from rat retinae and cDNA reverse transcribed using oligo dT primers. The relative expression of GLAST and EAAT4 was estimated using real-time PCR and amounts were corrected using the housekeeping gene, HPRT

increase by approximately $20 \%$ in diabetic retinae, this was not statistically significant.

Diabetic Müller cells have enhanced D-aspartate uptake Previous studies have suggested that glutamate turnover is likely to be abnormal in diabetes [15, 16, 25, 27]. D-Aspartate is a non-metabolisable substrate for GLAST. Quantification of the level of D-aspartate taken up by glial cells is a well established method for examining the function of glutamate transporters [30, 31, 37]. We evaluated glutamate uptake in Müller cells, by examining the level of uptake of D-aspartate in Müller cells. Because our ultimate aim was to evaluate the level of D-aspartate uptake in Müller cells following intravitreal injection, it was first necessary to confirm that the concentration of injected D-aspartate saturates the transport system. Figure 3a shows D-aspartate immunoreactivity in the rat retina following incubation for $10 \mathrm{~min}$ in $0.3 \mathrm{mmol} / \mathrm{l} \mathrm{D}$-aspartate. D-aspartate labelled Müller cell somata in the inner nuclear layer (INL), their end feet and processes extending radially throughout the outer nuclear layer (ONL) and inner plexiform layer (IPL). This is a similar pattern of immunoreactivity to that previously described $[30,37]$. By contrast, D-aspartate immunoreactivity was immunonegative in tissue that had been incubated in no D-aspartate (data not shown). The relative change in D-aspartate immunoreactivity in Müller cells as a function of the logarithm of the exogenous concentration of D-aspartate is shown in Fig. 3b. An $\mathrm{EC}_{50}$ value (exogenous concentration of $\mathrm{D}$-aspartate required for half the maximum change in D-aspartate immunoreactivity) was determined from this graph. The $\mathrm{EC}_{50}$ value was found to be $49 \mu \mathrm{mol} / \mathrm{l}$. Therefore, injecting 100-370 $\mu \mathrm{mol} / 1 \mathrm{D}$-aspartate would represent concentrations that should be reliably quantifiable.

Uptake of D-aspartate was examined following 1, 4 and 12 weeks of diabetes. We observed very little D-aspartate uptake into Müller cells following injection with $0.1 \mathrm{mmol} / 1$ D-aspartate (data not shown). However, injection with $0.37 \mathrm{mmol} / \mathrm{l} \mathrm{D}$-aspartate resulted in a reproducible and 
Fig. 3a Micrograph showing D-aspartate immunoreactivity in the normal rat retina following a 10 -min incubation in $0.3 \mathrm{mmol} / 1$ aspartate. D-Aspartate labelled Müller cell somata (arrowhead), and their processes extending to the outer and inner limiting membrane. Scale bar $=20 \mu \mathrm{m}$ b Graph showing the quantification of the relative change in D-aspartate immunoreactivity in Müller cell somata following 10 -min incubations in varying concentrations of D-aspartate
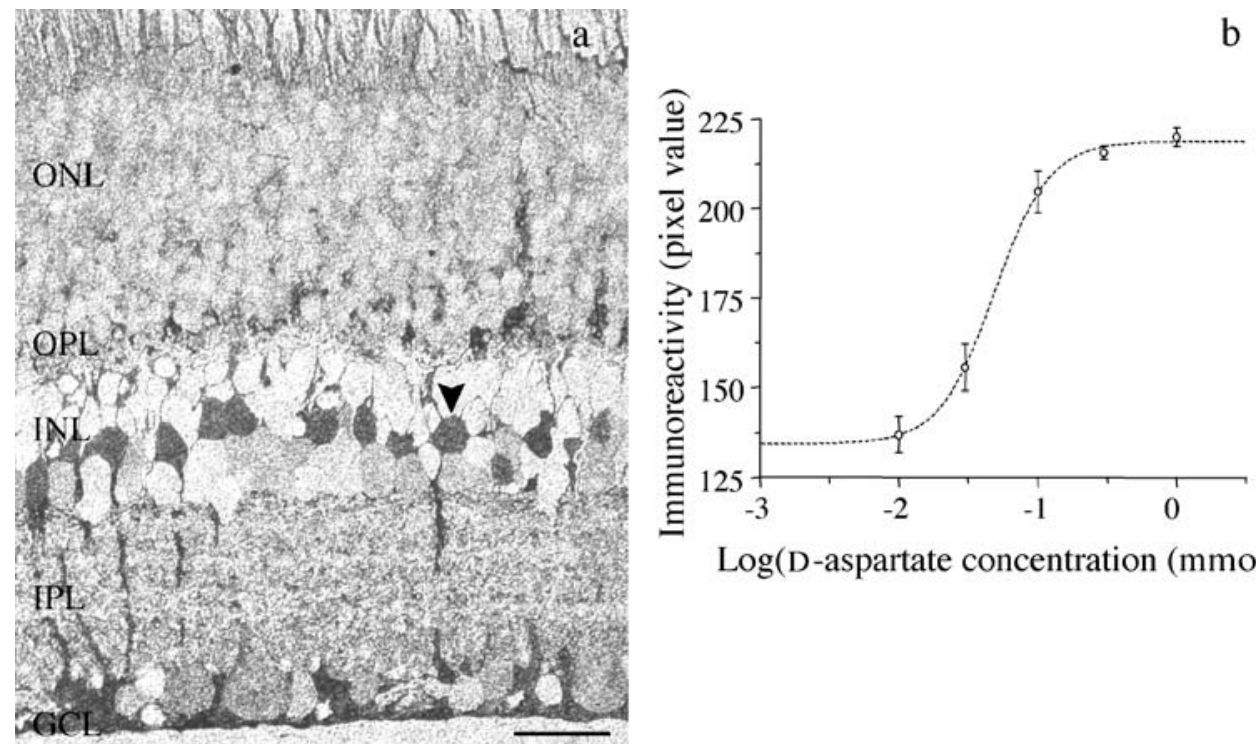

Log(D-aspartate concentration (mmol/l)
Fig. 4 Micrographs showing D-aspartate immunoreactivity in control (a, c, e) and diabetic $(\mathbf{b}, \mathbf{d}, \mathbf{f})$ rat retinae that had been injected intravitreally with D-aspartate following 1 (a, b), 4 (c, d) and $12(\mathbf{e}, \mathbf{f})$ weeks of diabetes. At all stages examined, D-aspartate was taken up into Müller cell somata. Müller cells from diabetic retinae appear more intensely labelled for D-aspartate, indicating that glutamate transport is enhanced. Abbreviations as in Fig. 1. Scale bar $=20 \mu \mathrm{m}$
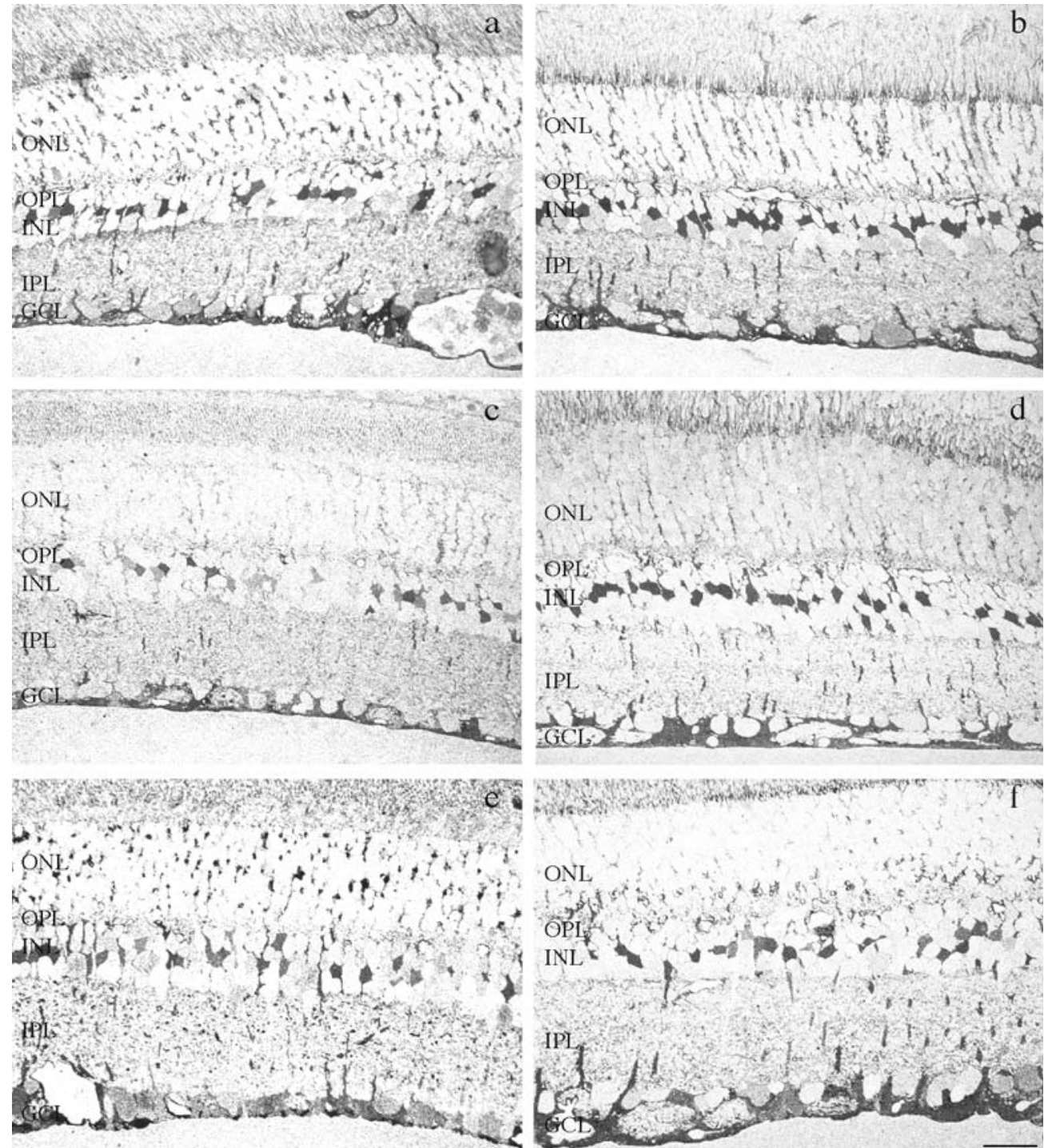


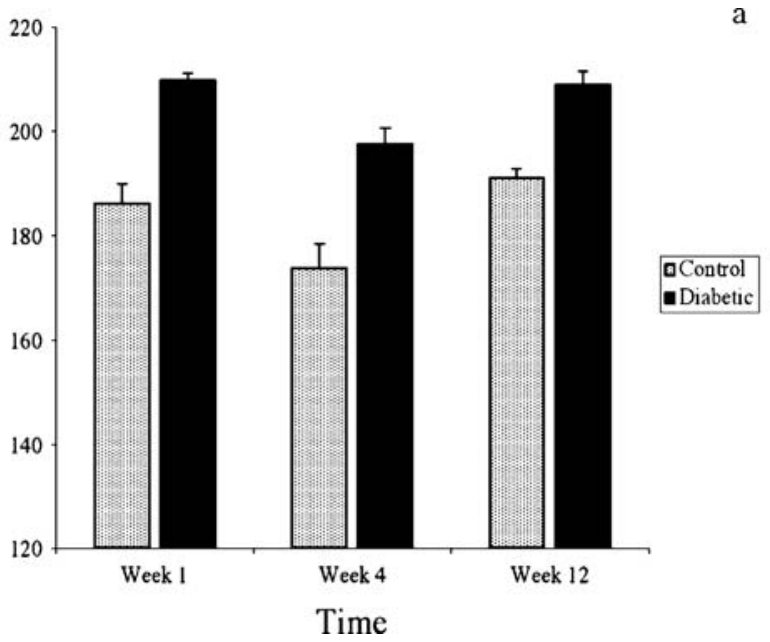

Fig. 5 a Graph showing the mean $( \pm$ SEM) relative change in Daspartate immunoreactivity in Müller cell somata from control and diabetic retinae following 1, 4 or 12 weeks of diabetes. At all stages examined, D-aspartate uptake was enhanced in diabetic Müller cells compared with controls. b Graph showing the dose-response curve for D-aspartate immunoreactivity in Müller cell somata following

quantifiable uptake into Müller cells. Although the concentration of D-aspartate may appear high in relation to the $\mathrm{EC}_{50}$, it should be noted that this is merely an estimate of the vitreal D-aspartate concentration based on a presumed vitreal volume. Figure 4 shows control and diabetic retinae labelled for D-aspartate at 1, 4 and 12 weeks following onset of diabetes. D-Aspartate immunoreactivity was found to intensely label Müller cell somata and processes in all of the retinae examined. In addition, there appeared to be a higher level of D-aspartate immunoreactivity in diabetic retinae compared to controls. We quantified the relative difference in D-aspartate immunoreactivity (pixel value) in control and diabetic Müller cells (Fig. 5a). At all stages of diabetes examined, D-aspartate uptake was greater in diabetic Müller cell somata compared with controls (Fig. 5a; ANOVA, $p<0.0001)$. Although D-aspartate uptake was higher in diabetic Müller cells following 4 weeks of diabetes than controls, it was significantly less than that observed following either 1 or 12 weeks of diabetes. This may reflect an improvement in retinal function at this stage of diabetes. It is not clear why this functional improvement might occur, but it could be related to toxic effects of the STZ injection following 1 week and true hyperglycaemic effects at later stages of diabetes.

In order to verify the significance of this increase in Daspartate uptake we floated the mean D-aspartate values generated from the intravitreal experiment onto our doseresponse curve generated in Fig. 3b (Fig. 5b). By doing this, we were able to approximate the change in $\mathrm{EC}_{50}$ value in D-aspartate uptake in control and diabetic retinae. There was a difference of $0.304 \log$ units between the $\mathrm{EC}_{50}$ value for the controls and diabetics (Fig. 5b; Control, $\left.\log \mathrm{EC}_{50}=-1.309 ; \mathrm{STZ}, \log \mathrm{EC}_{50}=-1.613\right)$. Based on this approximation, $\mathrm{D}$-aspartate transport in diabetic retinal

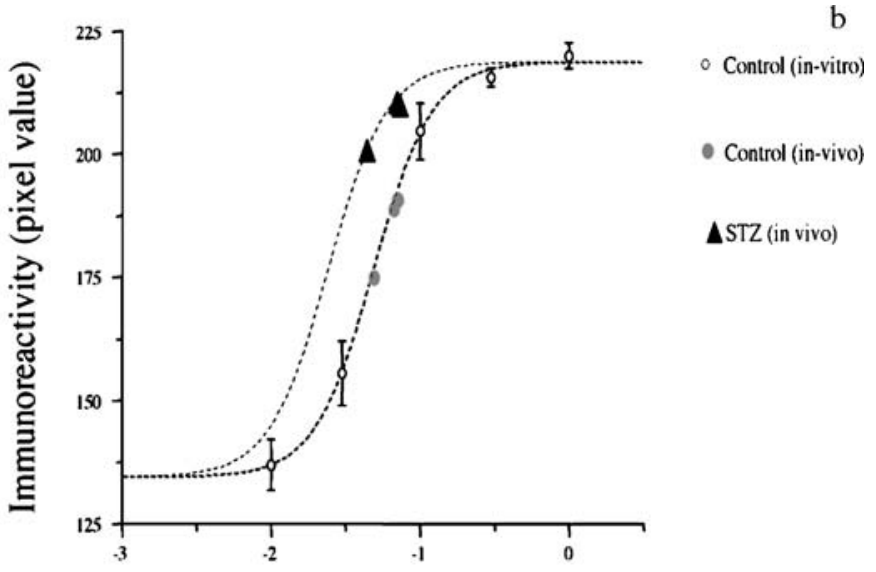

\section{Log(D-aspartate concentration ( $\mathrm{mmol} / \mathrm{l}))$}

incubation in varying concentration of D-aspartate. The mean Daspartate pixel values from control and diabetic retinae were floated onto the dose-response curve taken from Fig. 3b. There was a 0.304 $\log$ unit change in the $\mathrm{EC}_{50}$ value for D-aspartate in control and diabetic Müller cells. This suggests that glutamate uptake by diabetic Müller cells is approximately twice as efficient as in controls

Müller cells is twice as efficient as transport by Müller cells in age-matched controls.

\section{Discussion}

Abnormalities in glutamate recycling are known to have deleterious effects on the function of retinal neurons in a number of retinal diseases. In this study we examined the expression of two glutamate transporters and evaluated the function of GLAST, the major glutamate transporter in the retina. We found that expression of GLAST and EAAT4 was unchanged following 12 weeks of diabetes but that, functionally, glutamate uptake was enhanced, even after a short period of diabetes.

There are two major classes of macroglial cells within the retina; Müller cells are the predominant glial cell type and express the glutamate transporter GLAST $[8,13,21]$. It is well known that GLAST provides the bulk of glutamate uptake within the retina $[23,24,38]$. Indeed, loss of function of GLAST results in a major loss of retinal structure and function. To our surprise we observed an increase D-aspartate uptake even at an early stage of diabetes. This finding is at odds with those demonstrated by $\mathrm{Li}$ and Puro [27], who showed that the 1-trans-pyrrolidine-2,4-dicarboxylate-induced current in isolated Müller cells was less in diabetic Müller cells than controls. Although it is not clear why our results differ, it should be emphasised that we used an in vivo measurement to assess uptake, rather than examination of this aspect in isolated cells. Experimentation on isolated cells may not always reflect function in vivo because the external environment is artificially controlled. This may be particularly significant in studying the changes in cellular function during diabetes because the 
external milieu can be altered by breakdown of the bloodretinal barrier [28].

There are several possible explanations for the observed increase in glutamate uptake during diabetes. The function of GLAST is not directly dependent on the protein expression within a tissue. Like other amino acid transporters, function is dependent on translocation of the protein between the plasma membrane and intracellular storage compartments. Alterations in cell-surface expression can up- or down-regulate membrane proteins within minutes, far more rapidly than is possible by protein synthesis (for review see Danbolt [39]). Examples of such mechanisms can be observed for glucose transporters; GLUT4 moves to the plasma membrane in response to insulin. Similarly, membrane expression of transporters for GABA, glycine and serotonin use similar mechanisms. In terms of glutamate transporters, EAAC1 has been shown to translocate to the cell surface of $\mathrm{C} 6$ glioma cells in response to activation by protein kinase $\mathrm{C}$ [40]. Although little information is available on the intracellular concentrations of GLAST in brain or retinal glia, two studies highlight the importance of this mechanism for rapid changes in GLAST function in the glia. Duan et al. [41] demonstrated rapid changes in surface expression of GLAST in murine astrocytes in response to exogenous glutamate. Payet et al. [42] recently showed that hypoxia caused an dramatic increase in GLAST function in isolated retinal cells, an effect that was blocked by treatment with cytochalasin B, an inhibitor of actin polymerisation. We propose that GLAST function increases during diabetes, in the absence of a change in mRNA expression, because of a mobilisation of protein to the cell surface of Müller cells. Further work is necessary to definitively understand the mechanisms involved in this form of transporter regulation.

There are several factors that can regulate GLAST function and possible cell surface expression. Glutamate is known to trigger a rapid increase in surface expression of GLAST and EAAT4 [41]. Other factors that may play a role include activation of glutamate receptors on glia [43], modulation of GLAST expression by growth factors such as insulin growth factor-1, oxidative stress [44], arachidonic acid [45], or protein kinase C [46]. Other factors such as plasma that leak from the break down of the blood-retinal barrier can also alter ion channel conductance within Müller cells [29]. Clearly, GLAST function could be altered by any of the myriad of biochemical changes that are known to occur during diabetic retinopathy.

It is well known that a fully functional glutamate turnover system is required for normal neuronal function. Indeed, many conditions such as amyotrophic lateral sclerosis, Alzheimer's disease, and neuronal death following ischaemia, have been linked with abnormalities in glutamate transport, and in particular a decrease in glial glutamate transport [39]. Indeed, Lieth et al. [16] suggest that a decrease in glutamate transporter function could explain the neuronal dysfunction and possibly neuronal apoptosis that occurs during diabetes $[5,47,48]$. Essentially, an elevation of extracellular glutamate concentrations is known to lead to excitotoxic stimulation and subsequent death of neurons.

We observed a doubling of glutamate uptake capacity in diabetic Müller cells compared to controls. It is interesting to note that this is not the first retinal or CNS disease associated with an increase in glutamate transporter function. Indeed, following hypoxia, glutamate uptake is enhanced in isolated retinal cells [42]. Moreover glutamate transporter expression is enhanced in the thalamus of patients with schizophrenia [49]. In schizophrenia, the hyperfunction of GLAST is thought to play a significant role in the disease process. In particular, Smith et al. [49] suggest that the hyperfunction of GLAST may be linked with a decrease in NMDA receptor expression in schizophrenia [50]. An increase in glutamate uptake capacity would lower the concentrations of glutamate within synapses to levels below that normally found. This could have downstream effects such a reduction in glutamate receptor expression and function. There are no reports of changes in glutamate receptor expression in the retina during diabetes. However, it is well known that there are a myriad of neuronal changes [1-7]. It is possible that some of the neuronal dysfunction reported to occur during diabetes could arise because of an abnormality of glutamate transport and concomitant glutamate receptor expression changes. Further work is necessary to address this issue.

Several reports have suggested that there is neuronal death within the retina during diabetes [16, 46, 47]. Our results demonstrating an increase in glutamate uptake suggest that glutamate neurotoxicity is unlikely to play a major role in causing neuronal apoptosis. The reported increases in glutamate concentrations in the vitreous could arise from the breakdown in the blood-retinal barrier [15] and bloodaqueous barrier. However, the extracellular concentration of glutamate within the retina would be maintained at "safe" levels.

In summary, our results indicate that although there is no change in expression of GLAST or EAAT4 there is an increase in glutamate uptake by Müller cells as early as one week following the induction of diabetes. These results suggest that although Müller cells undergo gliosis at an early stage of diabetes, one of the most important functions for maintaining normal retinal function is preserved. Further work is necessary to determine whether the observed elevation in glutamate transporter function is linked with neuronal dysfunction.

Acknowledgements The authors gratefully acknowledge the assistance of Ms Riki Gibson. This work was supported by a grant from the National Health and Medical Research Council to ELF (\#208950) and supported in part by a professorship provided by the Robert G. Leitl estate (M.K.). No authors have any conflicts of interest.

\section{References}

1. Lieth E, Gardner TW, Barber AJ, Antonetti DA (2000) Retinal neurodegeneration: early pathology in diabetes. Clin Experiment Ophthalmol 28:3-8 
2. Terasaki H, Hirose H, Miyake Y (1996) S-cone pathway sensitivity in diabetes measured with threshold versus intensity curves on flashed backgrounds. Invest Ophthalmol Vis Sci 37:680-684

3. Kurtenbach A, Schiefer U, Neu A, Zrenner E (1999) Preretinopic changes in the colour vision of juvenile diabetics. Br J Ophthalmol 83:43-46

4. Holopigian K, Greenstein VC, Seiple W, Hood DC, Carr RE (1997) Evidence for photoreceptor changes in patients with diabetic retinopathy. Invest Ophthalmol Vis Sci 38:2355-2365

5. Shirao Y, Kawasaki K (1998) Electrical responses from diabetic retina. Prog Retin Eye Res 17:59-76

6. Fortune B, Schneck ME, Adams AJ (1999) Multifocal electroretinogram delays reveal local retinal dysfunction in early diabetic retinopathy. Invest Ophthalmol Vis Sci 40:2638-2651

7. Han Y, Bearse MA Jr, Schneck ME, Barez S, Jacobsen CH, Adams AJ (2004) Multifocal electroretinogram delays predict sites of subsequent diabetic retinopathy. Invest Ophthalmol Vis Sci 45:948-954

8. Ripps H, Witkovsky P (1985) Neuron-glia interaction in the brain and retina. In: Osborne NN, Chader GJ (eds) Progress in retinal research Vol 4. Pergamon Press, Oxford, pp 181-219

9. Pow DV, Robinson SR (1994) Glutamate in some retinal neurons is derived solely from glia. Neuroscience 60:355-366

10. Hertz L (1979) Functional interactions between neurons and astrocytes. I. Turnover and metabolism of putative amino acid transmitters. Prog Neurobiol 13:277-323

11. Tout S, Chan-Ling T, Hollander H, Stone J (1993) The role of Müller cells in the formation of the blood-retinal barrier. Neuroscience 55:291-301

12. Zahs KR, Wu T (2001) Confocal microscopic study of glialvascular relationships in the retinas of pigmented rats. J Comp Neurol 429:253-269

13. Rauen T, Rothstein JD, Wässle H (1996) Differential expression of three glutamate transporter subtypes in the rat retina. Cell Tissue Res 286:325-336

14. Ward MM, Jobling AI, Puthussery T, Foster LM, Fletcher EL (2004) Localization and expression of the glutamate transporter, excitatory amino acid transporter 4 , within astrocytes of the rat retina. Cell Tissue Res 315:305-310

15. Ambati J, Chalam KV, Chawla DK et al. (1997) Elevated gamma-aminobutyric acid, glutamate, and vascular endothelial growth factor levels in the vitreous of patients with proliferative diabetic retinopathy. Arch Ophthalmol 115:1161-1166

16. Lieth E, Barber AJ, Xu B et al. (1998) Glial reactivity and impaired glutamate metabolism in short-term experimental diabetic retinopathy. Diabetes 47:815-820

17. Massey SC (1990) Cell types using glutamate as a neurotransmitter in the vertebrate retina. In: Osborne NN, Chader CJ (eds) Progress in retinal research vol 8. Pergamon Press, Oxford, pp 399-425

18. Danbolt NC, Chaudhry FA, Dehnes Y et al. (1998) Properties and localization of glutamate transporters. Prog Brain Res 116: $23-43$

19. Arriza JL, Eliasof S, Kavanaugh MP, Amara SG (1997) Excitatory amino acid transporter 5 , a retinal glutamate transporter coupled to a chloride conductance. Proc Natl Acad Sci U S A 94:4155-4160

20. Pow DV, Barnett NL (2000) Developmental expression of excitatory amino acid transporter 5: a photoreceptor and bipolar cell glutamate transporter in rat retina. Neurosci Lett 280:21-24

21. Lehre KP, Davanger S, Danbolt NC (1997) Localization of the glutamate transporter protein GLAST in rat retina. Brain Res 744:129-137

22. Reye P, Sullivan R, Fletcher EL, Pow DV (2002) Distribution of two splice variants of the glutamate transporter GLT1 in the retinas of humans, monkeys, rabbits, rats, cats, and chickens. J Comp Neurol 445:1-12

23. Harada T, Harada C, Watanabe M et al. (1998) Functions of the two glutamate transporters GLAST and GLT-1 in the retina. Proc Natl Acad Sci U S A 95:4663-4666
24. Rauen T, Taylor WR, Kuhlbrodt K, Wiessner M (1998) Highaffinity glutamate transporters in the rat retina: a major role of the glial glutamate transporter GLAST-1 in transmitter clearance. Cell Tissue Res 291:19-31

25. Lieth E, LaNoue KF, Antonetti DA, Ratz M (2000) Diabetes reduces glutamate oxidation and glutamine synthesis in the retina. Exp Eye Res 70:723-730

26. Lo TC, Klunder L, Fletcher EL (2001) Increased Müller cell density during diabetes is ameliorated by aminoguanidine and ramipril. Clin Exp Optom 84:276-281

27. Li Q, Puro DG (2002) Diabetes-induced dysfunction of the glutamate transporter in retinal Müller cells. Invest Ophthalmol Vis Sci 43:3109-3116

28. Kusaka S, Kapousta-Bruneau N, Green DG, Puro DG (1998) Serum-induced changes in the physiology of mammalian retinal glial cells: the role of lysophosphatidic acid. J Physiol 506:445458

29. Kusaka S, Kapousta-Bruneau NV, Puro DG (1999) Plasmainduced changes in the physiology of mammalian retinal glial cells: role of glutamate. Glia 25:205-215

30. Barnett NL, Pow DV, Bull ND (2001) Differential perturbation of neuronal and glial glutamate transport systems in retinal ischaemia. Neurochem Int 39:291-299

31. Gunderson V, Danbolt NC, Ottersen OP, Storm-Mathisen J (1993) Demonstration of glutamate/aspartate uptake activity in nerve endings by use of antibodies recognizing exogenous Daspartate. Neuroscience 57:97-111

32. Kalloniatis M, Fletcher EL (1993) Immunocytochemical localization of the amino acid neurotransmitters in the chicken retina. J Comp Neurol 336:174-193

33. Marc RE, Liu WL, Kalloniatis M, Raiguel SF, van Haesendonck E (1990) Patterns of glutamate immunoreactivity in the goldfish retina. J Neurosci 10:4006-4034

34. Marc RE, Murry RF, Basinger SF (1995) Pattern recognition of amino acid signatures in retinal neurons. J Neurosci 15:51065129

35. Kalloniatis M, Marc RE, Murry R (1996) Amino acid signatures in the primate retina. J Neurosci 16:6807-6902

36. Napper GA, Kalloniatis M (1999) Neurochemical changes following postmortem ischemia in the rat retina. Vis Neurosci 16:1169-1180

37. Fletcher EL, Kalloniatis M (1996) Neurochemical architecture of the normal and degenerating rat retina. J Comp Neurol 376:343-360

38. Barnett NL, Pow DV (2000) Antisense knockdown of GLAST, a glial glutamate transporter, compromises retinal function. Invest Ophthalmol Vis Sci 41:585-591

39. Danbolt NC (2001) Glutamate uptake. Prog Neurobiol 65:1105

40. Dowd LA, Robinson MB (1996) Rapid stimulation of EAAC1mediated $\mathrm{Na}+$-dependent L-glutamate transport activity in C6 glioma cells by phorbol ester. J Neurochem 67:508-516

41. Duan S, Anderson CM, Stein BA, Swanson RA (1999) Glutamate induces rapid upregulation of astrocyte glutamate transport and cell-surface expression of GLAST. J Neurosci 19:10193-10200

42. Payet O, Maurin L, Bonne C, Muller A (2004) Hypoxia stimulates glutamate uptake in whole rat retinal cells in vitro. Neurosci Lett 356:148-150

43. Gegelashvili G, Civenni G, Racagni G, Danbolt NC, Schousboe I, Schousboe A (1996) Glutamate receptor agonists up-regulate glutamate transporter GLAST astrocytes. NeuroReport 8:261-265

44. Agostinho P, Duarte CB, Oliveira CR (1997) Impairment of excitatory amino acid transporter activity by oxidative stress conditions in retina cells: effect of antioxidants. FASEB J $11: 154-163$

45. Volterra A, Trotti D, Racagni G (1994) Glutamate uptake is inhibited by arachidonic acid and oxygen radicals via tow distinct and additive mechanisms. Mol Pharmacol 46:986-992 
46. Bull ND, Barnett NL (2002) Antagonists of protein kinase C inhibit rat retinal glutamate transport activity in situ. J Neurochem 81:472-480

47. Barber AJ, Lieth E, Khin SA, Antonetti DA, Buchanan AG, Gardner TW (1998) Neural apoptosis in the retina during experimental and human diabetes. Early onset and effect of insulin. J Clin Invest 102:783-791

48. Park SH, Park JW, Park SJ et al. (2003) Apoptotic death of photoreceptors in the streptozotocin-induced diabetic rat retina. Diabetologia 46:1260-1268
49. Smith RE, Haroutunian V, Davis KL, Meador-Woodruff JH (2001) Expression of excitatory amino acid transporter transcripts in the thalamus of subjects with schizophrenia. Am J Psychiatry 158:1393-1399

50. Ibrahim HM, Hogg AJ Jr, Healy DJ, Haroutunian V, Davis KL, Meador-Woodruff JH (2000) Ionotropic glutamate receptor binding and subunit mRNA expression in thalamic nuclei in schizophrenia. Am J Psychiatry 157:1811-1823 